\title{
Inflammation in cystic fibrosis airways: relationship to increased bacterial adherence
}

\author{
P. Scheid*, L. Kempster*, U. Griesenbach*, J.C. Davies*, A. Dewar", P.P. Weber", \\ W.H. Colledge ${ }^{+}$, M.J. Evans ${ }^{\S}$, D.M. Geddes*, E.W.F.W. Alton*
}

Inflammation in cystic fibrosis airways: relationship to increased bacterial adherence. $P$. Scheid, L. Kempster, U. Griesenbach, J.C. Davies, A. Dewar, P.P. Weber, W.H. Colledge, M.J. Evans, D.M. Geddes, E.W.F.W. Alton. C)ERS Journals Ltd 2001.

ABSTRACT: It is unclear whether inflammation in the cystic fibrosis (CF) lung relates predominantly to bacterial infection, or occurs as a direct consequence of mutant cystic fibrosis transmembrane conductance regulator (CFTR) protein.

Interleukin (IL)-8 secretion from CF and non-CF cell lines, and from $\mathrm{CF}$ and non-CF human primary nasal epithelial cells incubated with or without Pseudomonas aeruginosa, was measured. Activation of nuclear factor-кB $(\mathrm{NF}-\kappa \mathrm{B})$ in unstimulated $\mathrm{CF}$ and non-CF nasal epithelial cells, cell lines and murine tissues was measured by gelshift assays.

No significant difference in basal IL-8 production or NF-kB activation was observed between $\mathrm{CF}$ and non-CF primary nasal cells. However, $\mathrm{CF}$ cells exhibited a significantly $(p<0.01)$ increased IL-8 secretion following $P$. aeruginosa stimulation. Equalization of the increased $P$. aeruginosa adherence observed in CF cells, to non-CF levels, resulted in comparable IL-8 secretion. Further, IL-8 production did not differ with mutations which result in either correctly localized CFTR, or in partial/total mislocalization of this protein. Similar levels of NF-KB activation were observed in a number of organs of wildtype and CF mice. Finally, IL-8 secretion and NF-кB activity were not consistently increased in CF cell lines. Cos-7 cell transfection with plasmids expressing $\Delta F 508$ or G551D mutant CFTR protein resulted in increased activation of a p50-containing NFкB complex, but IL-8 secretion was similar to wild-type cells.

The authors conclude that the stimulus produced by Pseudomonas aeruginosa is the predominant inflammatory trigger in their models.

Eur Respir J 2001; 17: 27-35.

\begin{abstract}
*Dept of Gene Therapy, Imperial College at the National Heart and Lung Institute, London, UK, " Electron Microscopy and Microbiology Dept, Royal Brompton and Harefield Hospital, London, UK, ${ }^{+}$Dept of Physiology, University of Cambridge, Cambridge, UK, and School of Biosciences, Cardiff University, Cardiff, UK.
\end{abstract}

Correspondence: E.W.F.W. Alton, Dept of Gene Therapy, National Heart and Lung Institute, Manresa Road, London, SW3 6LR, UK.

Fax: 442073518340

Keywords: Cystic fibrosis transmembrane conductance regulator, endoplasmic reticulum, interleukin-8, nuclear factor- $\mathrm{kB}$, Pseudomonas aeruginosa

Received: April 32000

Accepted after revision July 312000

This study was supported by the Association Française de Lutte contre la Mucoviscidose, the Société de Pneumologie de Langue Française, the European Respiratory Society, the North Atlantic Treaty Organization, the Cystic Fibrosis Research Trust and a Wellcome Trust Senior Clinical Fellowship.
Over the last two decades, the life expectancy of patients with cystic fibrosis (CF) has improved dramatically, allowing median survival to reach thirty years. Cloning of the $\mathrm{CF}$ gene and subsequent investigations into the molecular physiology of the gene product have led to a better understanding of the disease. The CF gene encodes the cystic fibrosis transmembrane conductance regulator protein (CFTR), a chloride channel localized to the apical surface of epithelial cell membranes. More than $800 \mathrm{CF}$ mutations are classified into five groups based on the mechanism by which the function of CFTR is disrupted. Broadly, these include those in which no protein is produced (class I), protein which does not reach its correct location (class II), and those in which smaller amounts or less functional protein are correctly localized (classes III-V) [1]. The deletion of the amino acid phenylalanine at position $508(\Delta \mathrm{F} 508)$ in the CFTR protein accounts for $>70 \%$ of $\mathrm{CF}$ alleles in Caucasians and is an example of a class II mutation.

The most common cause of death in $\mathrm{CF}$ is respiratory failure as a result of chronic pulmonary infection and inflammation [2]. However, it is not clear whether the inflammation is simply a secondary response to infection, or whether the primary defect in CFTR is more directly linked to the generation of this inflammatory process. A number of lines of evidence link mutant CFTR with an increased susceptibility to infection. Most studies suggest that CF subjects show reduced mucociliary clearance, perhaps related to the primary defect. This, in turn, will predispose to infection by a variety of organisms [2]. Local host antimicrobial defences, such as $\beta$-defensins [3], may show impaired function as a result of alterations in 
airway surface fluid (ASF) electrolytes, although it is presently unclear whether CF ASF is indeed abnormal with regard to sodium or chloride content [4]. A controversial hypothesis suggests that there is a defect in ingestion of Pseudomonas aeruginosa by respiratory epithelial cells [5], likely to facilitate infection. Finally, the receptor for $P$. aeruginosa, the asialoglycolipid asialo-GM1, is significantly increased on the apical cell membrane of $\mathrm{CF}$ respiratory epithelium and may, therefore, promote infection by increasing adherence [6]. Thus, several studies support the hypothesis that mutant CFTR can lead to increased bacterial colonization and resultant inflammation.

The hypothesis of primary (endogenous) inflammation is based firstly on clinical observations of inflammation preceding detectable infection in $\mathrm{CF}$ neonates and young children. Thus, bronchoalveolar lavage fluid showed neutrophil infiltration, increased levels of interleukin (IL)-8 [7, 8] and a protease/antiprotease imbalance, but was negative for bacterial culture [7]. A recent study adds weight to the concept of endogenous inflammation [9]. Early inflammation was examined in human foetal airway xenografts in severe combined immunodeficient (SCID) mice. Significant increases in IL-8 secretion were seen from CF proximal airway grafts prior to infection, when compared to non-CF grafts. Neutrophil recruitment to the basal membrane and movement to the epithelial surface was also evident. This was slower and less marked in non-CF proximal airways. In distal airway xenografts, neutrophil migration was again observed in $\mathrm{CF}$ airways, but was not seen in non-CF tissues. One possible explanation for endogenous inflammation is that mutant (mistrafficked) CFTR protein may directly increase activation of the transcription factor nuclear factor- $\kappa \mathrm{B}$ $(\mathrm{NF}-\kappa \mathrm{B})[10]$. $\mathrm{NF}-\kappa \mathrm{B}$, and particularly the p50/p65 heterodimer, is involved in the regulation of a large number of proinflammatory mediators [11]. In addition, "protective" cytokines such as IL-10 which serve to terminate inflammation, and are also under the control of $\mathrm{NF}-\kappa \mathrm{B}$, have been shown to be significantly reduced in $\mathrm{CF}$ [12].

IL-8 is a powerful chemoattractant and is transcriptionally regulated by $\mathrm{NF}-\kappa \mathrm{B}$. IL-8 is involved in recruitment of neutrophils into the lung [13] or nasal mucosa [14] and is a central factor in the inflammatory response of the airways [15]. This study has examined whether there is evidence for basally increased IL-8 production and NF- $\mathrm{NB}$ activation to support the hypothesis directly linking mutant CFTR to inflammation. To assess the alternative hypothesis of inflammation following infection, it has been studied whether in $\mathrm{CF}$, stimulation with $P$. aeruginosa results in exaggerated production of IL-8, and whether this in turn relates to the characteristically increased adherence level of these organisms.

\section{Materials and methods}

\section{Patient population}

The study used 29 adult CF patients (21 males) with a mean (range) age of 29.2 (17-44) yrs. None were using nasally inhaled, oral or intravenous steroids and no patient was studied during an acute exacerbation. The genotype of each subject is included in the Results section. Eighteen nonsmoking healthy volunteers (11 males) with a mean age of $32.7(23-50)$ yrs served as controls. The protocol was approved by the Royal Brompton Hospital Ethics Committee and all subjects gave informed consent.

\section{Nasal epithelial cell harvesting}

Nasal epithelial cells were obtained by brushing the mucosa of the inferior turbinate of both nostrils with a $3 \mathrm{~mm}$ cytology brush (Diagmed, Thirsk, UK). Recovered cells were suspended in Ham's F12 medium (Gibco BRL, Paisley, UK), washed once and pelleted by pulse centrifugation $(13,000 \times g)$ in phosphate-buffered saline (PBS) and resuspended in Ham's F12. Cell numbers were quantified by microscopic examination in a standard haemocytometer counting chamber (Sigma, Poole, UK) and viability evaluated using the trypan blue exclusion assay. Subsequently, samples were divided into two groups for assessment of IL-8 secretion and bacterial adherence. Viability was again quantified after $24 \mathrm{~h}$.

\section{Bacterial strain}

A laboratory reference strain of $P$. aeruginosa (international antigenic typing scheme (IATS) serotype 0:1 (National Collection of Type Cultures 11440, American Type Culture Collection 3348), nonmucoid, piliated and gentamycin-sensitive) was used [16]. The bacteria were grown on blood agar plates for four consecutive days before overnight culture in tryptone soya broth (Unipath Ltd, Basingstoke, UK) to ensure piliation. Piliation status was confirmed by transmission electron microscopy. Briefly, bacteria were suspended in distilled water, placed onto formvar coated grids (Agar Scientific Ltd, Stansted, UK) and negatively stained with $0.65 \%$ sodium phosphotungstate. Subsequently, bacteria were pelleted by centrifugation at $160 \times g$ for $10 \mathrm{~min}$, supernatant was removed and the pellet resuspended in $1 \mathrm{~mL}$ of phosphate buffered saline (PBS). Bacterial concentration was quantified by spectrophotometry, with an optical density at 620 nanometers, of 0.1 corresponding to $\sim 2.5 \times 10^{8}$ bacteria, as previously described [17]. Bacterial dilutions were prepared in PBS.

\section{Pseudomonas stimulation assay}

Nasal epithelial cells were divided into two $400-\mu \mathrm{L}$ aliquots. $P$. aeruginosa at a final concentration of $\sim 5.2 \times 10^{7}$ bacterial $\cdot \mathrm{mL}^{-1}$ was added to one aliquot, whilst the second aliquot was used to determine basal IL-8 secretion in the absence of stimulation. Both aliquots were incubated at $37^{\circ} \mathrm{C}$ with $5 \%$ carbon dioxide. After $1 \mathrm{~h}, 50 \mu \mathrm{L}$ of supernatant were removed from each sample and immediately stored at $-20^{\circ} \mathrm{C}$ for subsequent IL-8 analysis. Gentamycin $\left(500 \mu \mathrm{g} \cdot \mathrm{mL}^{-1}\right)$ 
was added to each sample and the incubation was continued under the same conditions. After $24 \mathrm{~h}, 50 \mu \mathrm{L}$ of supernatant were removed from each aliquot and stored at $-20^{\circ} \mathrm{C}$. IL-8 quantification was carried out using a standard enzyme-linked immunosorbent assay (ELISA; Genzyme, Billinghurst, UK), with results expressed as IL-8 production $\cdot 10^{-5}$ live cells present at the start of the incubation.

Assessment of bacterial adherence by scanning electron microscopy

Adherence was assessed by a previously described technique [17]. Briefly, after incubation at $37^{\circ} \mathrm{C}$ for $1 \mathrm{~h}$, nasal brushings were spun through a 50\% Percoll gradient (Pharmacia-Biotech, St Albans, UK) at $4{ }^{\circ} \mathrm{C}$ at $13,000 \times g$ for $20 \mathrm{~min}$, to separate the nonadherent bacteria from bacteria attached to epithelial cells. The nonadherent bacteria pelleted at the base of the tube, whereas bacteria attached to epithelial cells remained at the percoll/PBS interface. This fraction was removed and cytospun at $20 \times g$ onto a thermanox coverslip (Emitech, Ashford, Kent, UK). Cells were fixed overnight with $2.5 \%$ cacodylate-buffered glutaraldehyde, washed in sodium cacodylate buffer and dehydrated with serial concentrations of ethanol and hexamethyldisilazane (TAAB Laboratories, Aldermaston, UK). Coverslips were then mounted onto aluminium stubs, coated with gold, and analysed through field-emission scanning electron microscopy (Hitachi S4000, Nissei Sangyo, Tokyo, Japan). Samples were coded and examined with the observer blinded to the incubation conditions. Bacterial binding, defined as direct contact of $P$. aeruginosa with the ciliated surface of the cells, was assessed in a mean \pm SEM of $41 \pm 3$ cells per sample. Adherence data are expressed as the mean \pm SEM of adherent bacteria per 10 cells.

\section{Equalization of Pseudomonas aeruginosa adherence}

As increased IL-8 secretion levels produced by CF cells may simply reflect the increased receptor number, the authors attempted to equalize bacterial adherence in $\mathrm{CF}$ and non-CF cells. Decreasing dilutions of the $P$. aeruginosa standard culture were applied to CF cells, until similar adherence levels were seen in CF and nonCF cells.

\section{Electrophoretic mobility shift assay}

Cell pellets were washed twice in ice-cold PBS (Sigma, Poole, UK) and lysed in $70 \mu \mathrm{L}$ of extraction buffer as previously described by PAHL et al. [18]. The authors assayed total cellular protein, since irrespective of intracellular localization, only activated $\mathrm{NF}-\kappa \mathrm{B}$ can form deoxyribonucleic acid (DNA)/protein complexes, and thus be visualized using the electrophonetic mobility shift assay (EMSA). Briefly, cells were resuspended in extraction buffer $(20 \mathrm{mM} \mathrm{N}$-[2-hydroxyethyl] piperazine-N'-[2-ethanesulfonic acid] (HEPES), pH 7.9, 350 $\mathrm{mM} \mathrm{NaCl}, 20 \%$ glycerol, $1 \%$ Nonidet (NP40), $0.5 \mathrm{mM}$ ethylenediamine tetraacetic acid (EDTA), $1 \mathrm{mM}$ ethyleneglycol-bis-( $\beta$-aminoethylether)-N,N,N',N'-tetraacetic acid (EGTA), $0.5 \mathrm{mM}$ dithiothreitol (DTT) plus protease inhibitors (0.2 trypsin inhibitor units (TIU) $\mathrm{mL}^{-1}$ aprotinin, $500 \mu \mathrm{M}$ 4-(2-aminoethyl)benzinesulphonyl fluoride (AEBSF), $1 \mathrm{mM}$ sodium orthovanadate, $10 \mathrm{mM}$ sodium fluoride) and incubated on ice for $30 \mathrm{~min}$. Cell debris was removed through centrifugation $(14,000 \times g 5 \mathrm{~min})$ and the protein concentration was determined by a modified Folin-Lowry method [19]. The gel shift assay system from Promega (Southampton, UK) was used and EMSA was carried out according to manufacturers recommendations. An oligonucleotide probe containing the $\kappa$ light chain enhancer consensus sequence binding site for $\mathrm{NF}-\kappa \mathrm{B}$ (5'-AGT TGA GGG GAC TTT CCC AGG C-3') was end-labelled with radiolabelled adenosine triphosphate ( ${ }^{32}$ P-ATP) (Amersham Life Science Ltd, Little Chalfont, UK). Each reaction used $10 \mu \mathrm{g}$ of cellular protein. Reaction products were resolved on 5\% nondenaturing polyacrylamide gels (Anachem, Luton, UK) at $10 \mathrm{~mA}$ for $3 \mathrm{~h}$ at $20^{\circ} \mathrm{C}$. Gels were then dried for $2 \mathrm{~h}$ at $80^{\circ} \mathrm{C}$ and exposed to Kodak Biomax MS film at $-80^{\circ} \mathrm{C}$. To identify the specificity of NF- $\mathrm{NB}$ binding, competition studies with an approximate 50-fold excess of unlabelled $\mathrm{NF}-\kappa \mathrm{B}$ consensus oligonucleotide were carried out. For supershift analysis, $2 \mu \mathrm{g}$ of either anti-p50, anti-p52, anti-cRel, anti-RelB or anti-p65 antibodies (Santa Cruz Biotechnology Inc., CA, USA) were added after the addition of labelled oligonucleotide and reactions were incubated for a further $45 \mathrm{~min}$ at room temperature. Quantification of NF- $\mathrm{KB}$ complexes was carried out by densitometry using LabScan and ImageMaster 1D software (Amersham Pharmacia Biotech, St. Albans, UK).

\section{Mice}

Lungs, trachea, liver, spleen and kidneys were removed from $\Delta \mathrm{F} 508$ homozygote CF mice (CFTR ${ }^{\operatorname{tm} 2 \mathrm{Cam}}$ ) [20] and non-CF littermates (age 6-12 weeks). To determine NF- $\kappa \mathrm{B}$ activity the tissues were mechanically homogenized in $1 \mathrm{~mL}$ of extraction buffer and processed for EMSA as described above. Each reaction used $20 \mu \mathrm{g}$ total protein.

\section{Cell culture}

Human CF cell lines used were tracheal epithelium

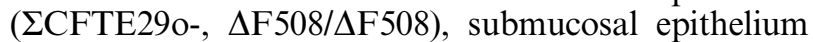
(CFSMEo-, $\triangle$ F508/unknown) and nasal polyp (CFNPE9o-, unknown/unknown). Human non-CF cell lines used were bronchial epithelium (16HBE14o-), tracheal epithelium (9HTEo-) and tracheo-bronchial epithelium (TBEo-). All cell lines were provided by Dieter Gruenert (University of California, San Francisco, CA, USA). CFNP9o-, इCFTE29o-, CFSMEoand $16 \mathrm{HBE} 14 \mathrm{o}-$ cells were cultured in minimal essential medium (MEM); 9HTEo- and TBEo- cells were grown in Dulbeccos modified Eagle medium (DMEM). Both media were supplemented with $10 \%$ foetal calf serum (FCS) and 1\% penicillin-streptomycin solution and cells 
grown in a $5 \% \mathrm{CO}_{2}$ atmosphere. All media, FCS and antibiotic solutions were obtained from Sigma (Poole, UK). Cultures were assayed for mycoplasma contamination using an ELISA assay (Boehringer Mannheim UK, Lewes, UK) and were shown to be free of infection. IL-8 secretion during $24 \mathrm{~h}$ incubation was determined in semiconfluent monolayers using a standard ELISA assay. To determine NF- $\kappa \mathrm{B}$ activation cells were grown to $70 \%$ confluence, scraped into surrounding medium and pelleted at $160 \times g$ for $5 \mathrm{~min}$ at room temperature and protein lysates were prepared as described above. The degree of cell confluence in immortalized cell culture may influence activation of $\mathrm{NF}-\kappa \mathrm{B}$ proteins. Thus, care was taken to ensure that all cell cultures were assayed at 70\% confluence. Cos- 7 cells (supplied by ATCC) were cultured under routine procedures in DMEM supplemented with 10\% FCS and $1 \%$ streptomycin/penicillin.

\section{Transfections}

The $6.2 \mathrm{~kb}$ wild-type, $\Delta$ F508 and G551D CFTR complementary deoxyribonucleic acids (cDNAs) were cloned into the Not I site of the eukaryotic expression vector pCMV $\beta$ (Clontech Laboratories UK Ltd, Basingstoke, UK), from which the $\beta$-galactosidase reporter gene was removed through Not I digestion. DNA was prepared using Qiagen columns (Qiagen Ltd, West Sussex, UK), according to manufacturers recommendations. Transient transfection of semiconfluent Cos-7 cells was carried out using plasmids complexed to the cationic lipid DC-Cholesterol/dioleylphosphatidylethanolamine (DOPE) at a ratio of 1:3 (44.8 $\mu \mathrm{g}$ plasmid: $134.4 \mu \mathrm{g}$ lipid per $80 \mathrm{~cm}^{2}$ flask) in Optimem (Sigma). The medium was replaced with normal growth medium $24 \mathrm{~h}$ after transfection. IL- 8 was determined $48 \mathrm{~h}$ after transfection and NF- $\mathrm{BB}$ activity was determined as described above.

\section{Statistical analysis}

The Mann-Whitney U-test was used to compare means and the Wilcoxon rank sum test to assess significance of changes from background levels. The null hypothesis was rejected at $\mathrm{p}<0.05$. Data are presented as mean \pm SEM for convenience. Numbers of human subjects or mice are indicated by $\mathrm{n}$ numbers, where appropriate.

\section{Results}

\section{Interleukin-8 secretion by nasal epithelial cells}

In the absence of added $P$. aeruginosa, IL-8 secretion at $24 \mathrm{~h}$ from freshly obtained $\mathrm{CF}(\mathrm{n}=19)$ and non-CF $(n=16)$ primary nasal epithelium was not significantly different (fig. 1). Incubation with $P$. aeruginosa resulted in a significant $(\mathrm{p}<0.05)$ increase in IL-8 secretion after $24 \mathrm{~h}$ from $\mathrm{CF}$, but not from non-CF nasal cells. Thus, in the presence of $P$. aeruginosa, IL-8 secretion from $\mathrm{CF}$ cells was approximately three-fold higher than from

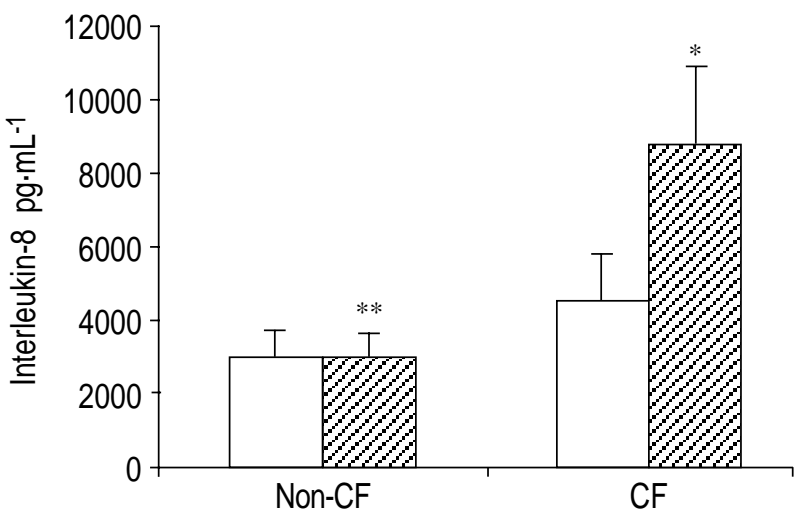

Fig. 1. - Interleukin-8 secretion assayed over $24 \mathrm{~h}$ from nasal epithelial cells under basal conditions and following exposure to Pseudomonas aeruginosa (cystic fibrosis (CF) $\mathrm{n}=19$, non-CF $\mathrm{n}=16$ ). Error bars indicate SEM. $\square$ : without $P$. aeruginosa; $\mathbb{Z}$ : with $P$. aeruginosa; *: $\mathrm{p}<0.05$ versus unstimulated $\mathrm{CF}$ cells; **: $\mathrm{p}<0.01$ versus stimulated CF cells.

non-CF cells $(\mathrm{p}<0.01)$. Assessment of cell viability by trypan blue exclusion and evidence of ciliary beating demonstrated that there was no significant difference in the number of live cells at $24 \mathrm{~h}$ after stimulation $(\mathrm{CF}$ : $1.8 \pm 0.6 \times 10^{5} \cdot \mathrm{mL}^{-1}, \mathrm{n}=11$; non-CF: $1.7 \pm 0.5 \times 10^{5} \cdot \mathrm{mL}^{-1}$, $\mathrm{n}=8)$.

Equalization of Pseudomonas aeruginosa adherence levels in cystic fibrosis and non-cystic fibrosis cells

It has previously been demonstrated using these methods that $P$. aeruginosa adherence to $\mathrm{CF}$ cells is $\sim 3-4$ times greater than to non-CF cells [17]. As this may have been the stimulus for IL- 8 production, the authors attempted to equalize the numbers of adherent bacteria to $\mathrm{CF}$ and non-CF cells. The authors first assessed the highest concentration of $P$. aeruginosa which could be applied to non-CF cells without affecting their viability, as assessed by trypan blue exclusion and evidence of ciliary beating. A 1:4 dilution of the standard $P$. aeruginosa culture, corresponding to $1.6 \times 10^{8}$ bacteria $\cdot \mathrm{mL}^{-1}$, was the maximum tolerated concentration resulting in $4.5 \pm 0.6 P$. aeruginosa adhering per 10 cells $(n=7)$.

Next, the $P$. aeruginosa concentration applied to $\mathrm{CF}$ cells was reduced to produce similar levels of binding to that seen in non-CF cells (fig. 2a). This level of binding was reached for CF cells with a $P$. aeruginosa solution approximately six times less concentrated than for non$\mathrm{CF}$, corresponding to $2.5 \times 10^{7}$ bacteria $\cdot \mathrm{mL}^{-1}$. Viability, assessed at $24 \mathrm{~h}$, using these two concentrations of $P$. aeruginosa was not different in $\mathrm{CF}$ and non-CF cells.

Interleukin-8 secretion under conditions of similar Pseudomonas aeruginosa adherence

When levels of $P$. aeruginosa adherence were approximately equal, IL-8 production by $\mathrm{CF}(\mathrm{n}=13)$ and non-CF cells $(n=7)$ did not differ over a 24 h period (fig. 2). Note that IL-8 values for this comparison were normalized for the number of adherent bacteria 

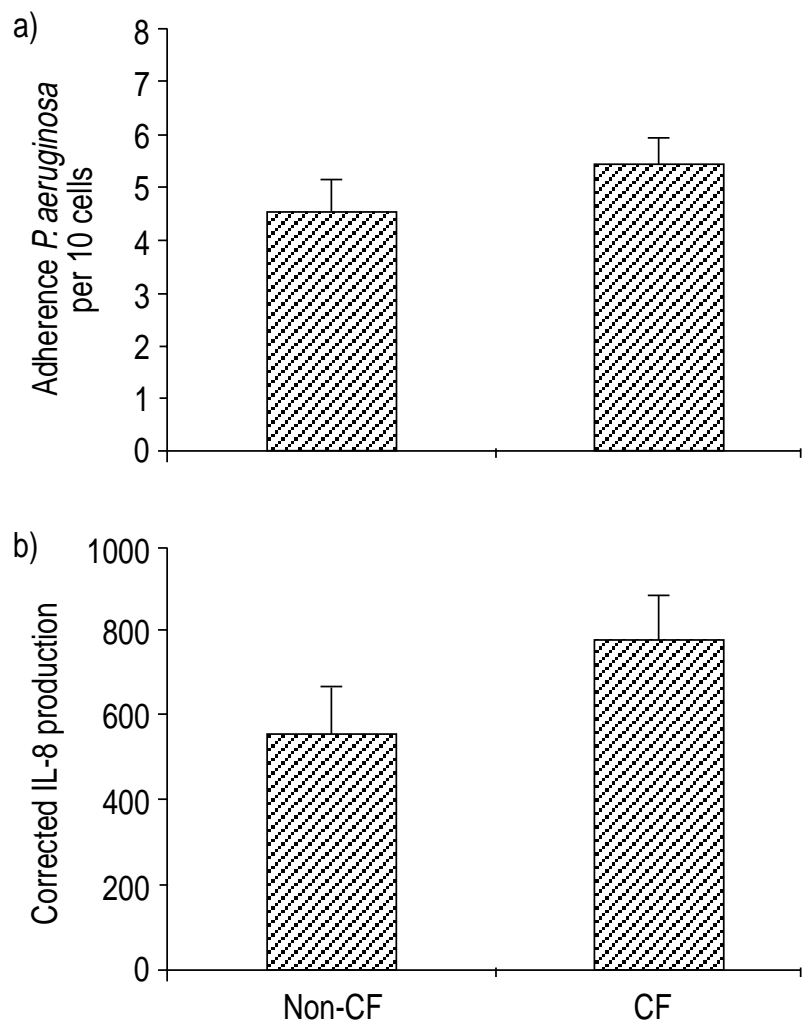

Fig. 2. - a) Equalization of Pseudomonas aeruginosa adherence between cystic fibrosis (CF) and non-CF cells. Cells were incubated with final concentrations of $1.6 \times 10^{8}$ and $2.5 \times 10^{7}$ bacteria $\cdot \mathrm{mL}^{-1}$, respectively. b) Interleukin-8 (IL-8) secretion from the same cells measured $24 \mathrm{~h}$ after stimulation (non-CF $\mathrm{n}=7, \mathrm{CF}$ $\mathrm{n}=13$ ). Note that the vertical axis represents IL- 8 in units of $\mathrm{pg} \cdot \mathrm{mL}^{-1}$, corrected for the number of adherent organisms in each individual sample. Error bars indicate SEM.

demonstrated for each subject to try to ensure greater accuracy. Because of this correction, values differ in magnitude from those shown in figure 1. As different concentrations of bacteria were applied to CF and non$\mathrm{CF}$ cells, adherence to the basolateral membrane was also examined to rule out any effects this may have on IL-8 secretion. No significant difference in the degree of basolateral adherence was observed between $\mathrm{CF}$ and non-CF cells (CF: $3.0 \pm 0.5 \cdot 10$ cells $^{-1}$; non-CF: $2.0 \pm 0.4 \cdot 10$ cells $\left.^{-1}\right)$.

\section{Influence of genotype}

To determine whether $\mathrm{CF}$ genotype influences $P$. aeruginos $a$ induced-IL-8 secretion, patients were classified into three groups. Group $1(\mathrm{n}=13)$ with mistrafficking mutations on both alleles $(\Delta \mathrm{F} 508$ homozygotes and a $\Delta$ F508/I507 compound heterozygote), group 2 $(n=6)$ with only one mistrafficking mutation $(\Delta F 508$ compound heterozygotes, the second mutation being $\mathrm{R} 553 \mathrm{X} \times 2, \quad 1717-1 \mathrm{G} \rightarrow \mathrm{A}, 621+1 \mathrm{G} \rightarrow \mathrm{T}, \mathrm{G} 551 \mathrm{D} \times 2)$, and group $3(\mathrm{n}=3)$ without mistrafficking mutations

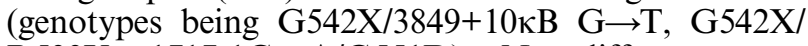
$\mathrm{R} 533 \mathrm{X}, \quad 1717-1 \mathrm{G} \rightarrow \mathrm{A} / \mathrm{G} 551 \mathrm{D})$. No difference was found in IL-8 secretion between the three groups (fig. 3).

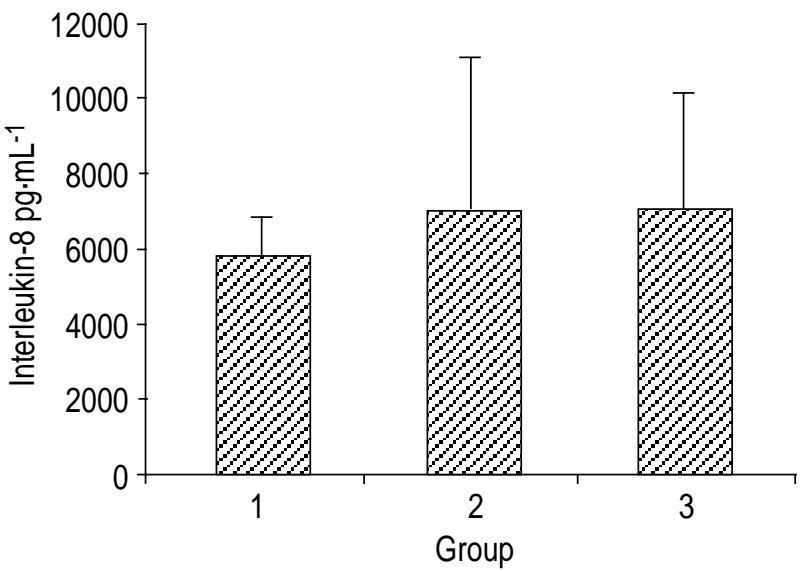

Fig. 3. - Influence of cystic fibrosis genotype on interleukin-8 secretion. Group 1: mistrafficking mutation on both alleles $(n=13)$; Group 2: one mistrafficking mutation $(n=6)$; Group 3: both nonmistrafficking mutations $(\mathrm{n}=3)$. Error bars indicate SEM.

Nuclear factor $-\kappa B$ activity in primary nasal epithelial cells and in cystic fibrosis murine tissues

EMSA assays using NF- $\kappa \mathrm{B}$ consensus oligonucleotides resulted in the appearance of three specific DNA/ protein complexes in all systems studied. A typical example from unstimulated 9HTEo- cell lysates is shown in figure 4. Only DNA/protein complexes I and II are increased after tumour necrosis factor- $\alpha$ (TNF- $\alpha$ ) and $P$. aeruginosa stimulation in cell lines and in mice (unpublished data). Complexes I and II were, therefore, quantified in combination in subsequent experiments as a marker of activated NF- $\kappa$ B. Supershifts indicated that complex II contains p50 protein, but the composition of complex I could not be determined (fig. 4). To eliminate any variations in complex I and II band density due to individual gel experimental procedures, bands of interest were standardized to the band density of a nonspecific band in each lane. NF- $\kappa \mathrm{B}$ activity was similar in freshly obtained primary nasal epithelial cells derived from $\mathrm{CF}(\mathrm{n}=4)$ and non-CF subjects $(n=5)$ (fig. 5).

These observations were extended to a comparison of $\mathrm{CF}$ and non-CF murine organs. There was also no significant difference in $\mathrm{NF}-\kappa \mathrm{B}$ activation in lung, trachea, spleen, kidney and liver of $\Delta$ F508 CF mice $(n=6)$ and wild-type littermates $(n=6)$ (fig. 5). For technical reasons it was not possible to assess the intestinal tract.

Nuclear factor- $\kappa B$ activity and interleukin-8 secretion in immortalized cell lines

CFNP9o- cells exhibited a significant decrease in activation of $N F-\kappa B(n=6, p<0.001)$ and no difference in IL-8 secretion when compared with the mean of the three non-CF cell lines (fig. 6). In CFSMEo- cells NF$\kappa \mathrm{B}$ activity was increased $(\mathrm{n}=6, \mathrm{p}<0.01)$, but IL-8 secretion was not different $(n=6)$. $\Sigma$ CFTE29o- cells showed an increased activation of NFKB $(n=6, p<0.001)$ and IL-8 secretion $(n=6, p<0.001)$. The increased NF- $\kappa B$ activity in CFSMEo- and $\Sigma$ CFTE29o- cells was largely due to an increase in complex II. 

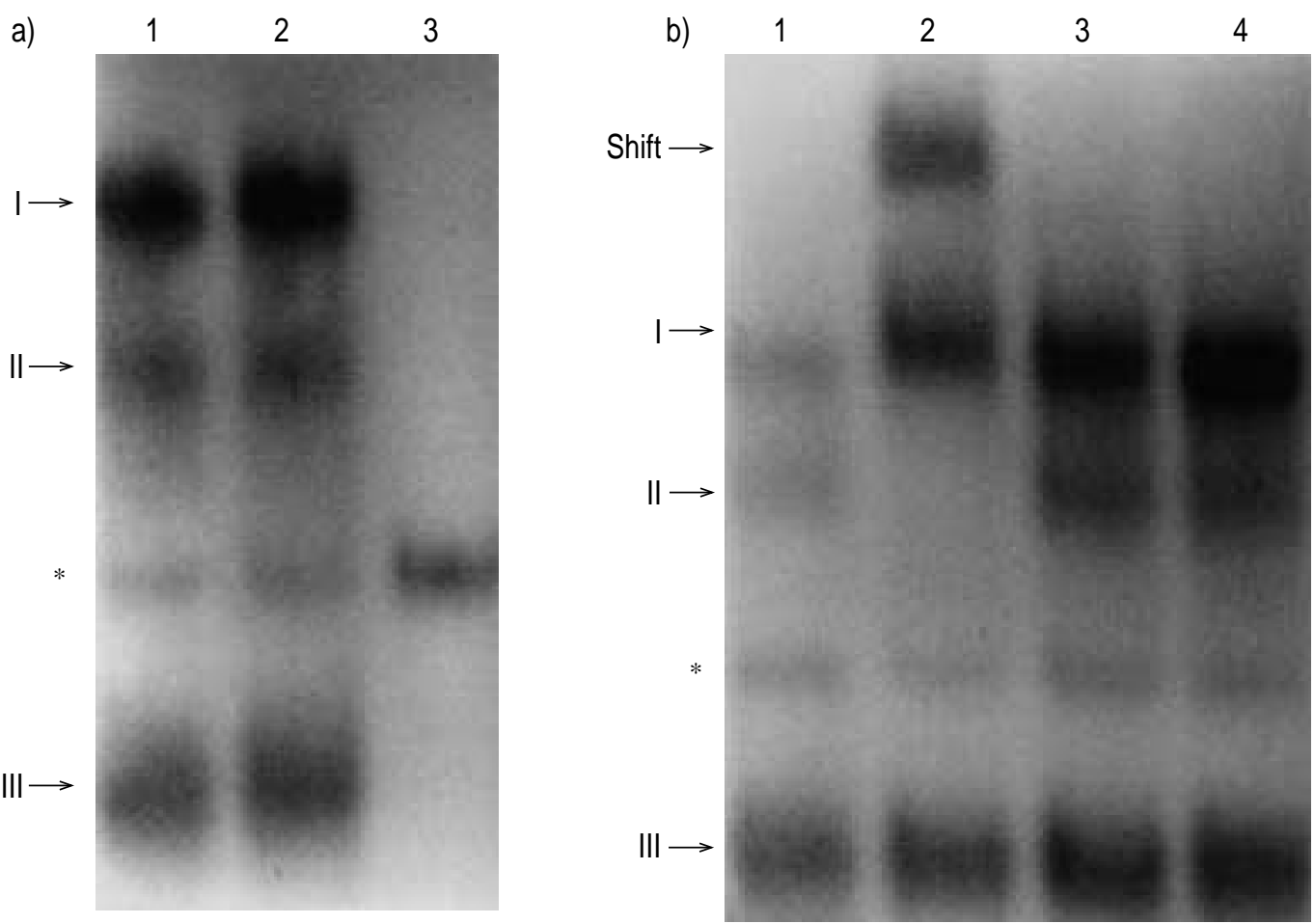

Fig. 4. - Electrophoretic mobility shift assay (EMSA) using unstimulated 9HTEo- cell lysates. EMSA assays carried out using a nuclear factor- $\mathrm{\kappa B}(\mathrm{NF}-\mathrm{\kappa B})$ consensus binding site resulted in three specific protein/deoxyribonucleic acid complexes. a) A typical example using lysate from unstimulated 9HTEo- cells. Lanes 1 and 2: Duplicate $10 \mu \mathrm{g}$ lysates incubated with radiolabelled NF- $\mathrm{KB}$ consensus binding site. Complexes I, II (p50 containing) and III are indicated. Lane 3: competition with unlabelled consensus oligonucleotide. *: nonspecific complex. b) Supershift assay using unstimulated 9HTEo- lysates. Lane 1: no added antibodies. Lanes 2-4: addition of antibodies specific to p50 (lane 2), p65 (lane 3) or c-Rel (lane 4) containing components of NF-kB. A shift occurred only with the antip50 antibody.

The effects of transfection with wild-type, $\Delta F 508$ and G551D cystic fibrosis transmembrane conductance regulator on nuclear factor- $\kappa B$ activity and interleukin-8 secretion

Cos-7 cells transfected with either $\Delta \mathrm{F} 508$ or G551D CFTR plasmids, exhibited a significant increase in p50containing complex II when compared to wild-type transfectants $(\mathrm{n}=10, \mathrm{p}<0.01)$ (fig. 7). No significant increase in complex I was observed. IL-8 secretion was not significantly different in any of the transfectants (fig. 7). Successful transfection was confirmed through plasmid-specific reverse transcriptase polymerase chain reaction (RT-PCR; data not shown). Following transfection with a $\beta$-galactosidase reporter gene $11 \pm 3 \%$ $(n=6)$ of cells were positive for an X-gal immunohistochemical assay. However, this assay is known to underestimate the overall transfection efficiency [21].

\section{Discussion}

In the present study, using freshly obtained human nasal epithelial cells, it has been demonstrated that the elevated IL- 8 secretion produced by CF cells in the presence of $P$. aeruginosa is a direct consequence of increased bacterial binding. No increase in basal NF- $\kappa \mathrm{B}$ activity could be detected in primary $\mathrm{CF}$ nasal epithelial cells or in CF mice. NF- $\mathrm{CB}$ activity and IL-8 secretion varied greatly between $\mathrm{CF}$ cell lines and neither was consistently increased, nor did they correlate with each other. Overexpression of $\Delta \mathrm{F} 508$ and G551D mutant CFTR increased p50 activity in Cos-7 cells when compared to overexpression of wild-type CFTR; however, this increase was not accompanied by an increase in IL8 secretion. Each of these studies has its limitations, but taken together the present findings lend support to the view that inflammation in $\mathrm{CF}$ relates predominantly to the bacterial burden in the airways of these patients.

There are substantial clinical data supporting the role of micro-organisms as the key initiator of $\mathrm{CF}$ inflammation [22, 23]. Many pathogens are implicated in bronchial infection in $\mathrm{CF}$ including Haemophilius influenzae, Staphylococcus aureus, $P$. aeruginosa and respiratory syncytial virus (RSV). Each of the bacteria, and in particular $P$. aeruginosa, bind to asialo-GM1 receptors via pili, inducing subsequent IL-8 production; no IL-8 upregulation is observed using unpiliated $P$. aeruginosa. Thus, these findings are in keeping with the authors' suggestion that the characteristic CF inflammation is linked to the increase in $P$. aeruginosa adherence. The increased numbers of asialo-GM1 receptors on $\mathrm{CF}$ cells may be a direct result of a $\mathrm{CF}$ mutation-related sialylation defect [24]. Thus, a reduction of $P$. aeruginosa adherence to nasal epithelial cells has been shown following transfection of wild-type CFTR [17].

Whilst $P$. aeruginosa adherence clearly triggers $\mathrm{CF}$ inflammation, other clinical studies suggest that inflammation may precede bacterial colonization. This is 

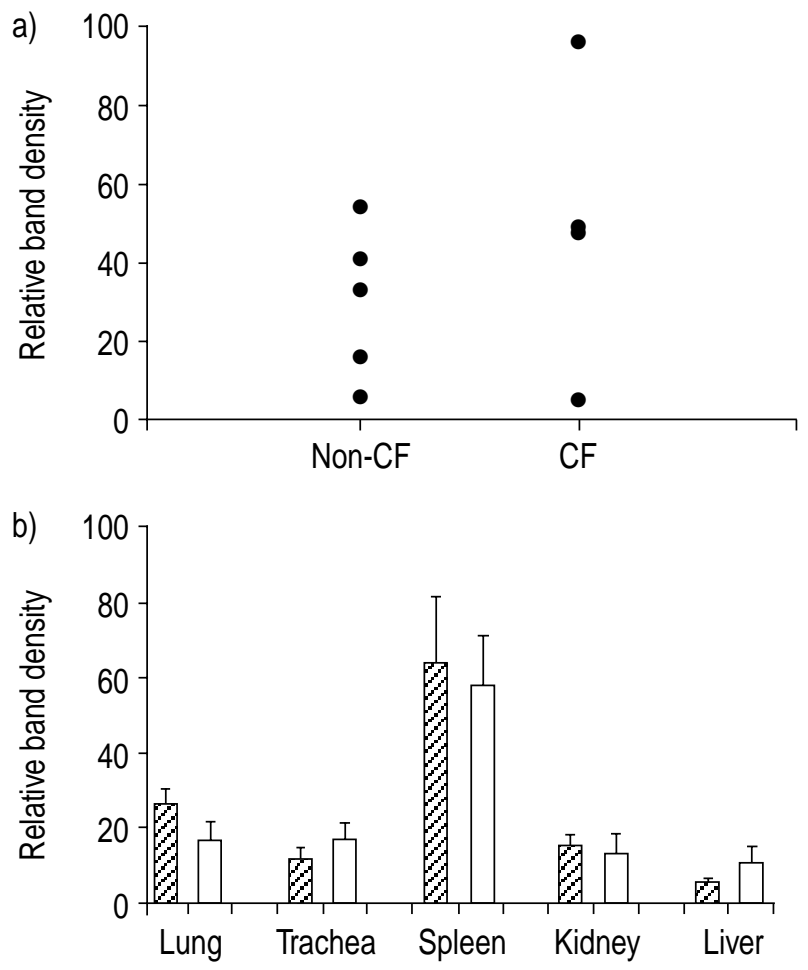

Fig. 5. - Quantification of total nuclear factor- $\kappa \mathrm{B}(\mathrm{NF}-\kappa \mathrm{B})$ activity in cystic fibrosis $(\mathrm{CF})$ and non-CF primary nasal epithelial cells and $\mathrm{CF}$ and non-CF murine tissues. a) Nasal epithelial cells from non-CF $(n=5)$ and $\triangle F 508$ CF subjects $(n=4)$. b) Tissues from wild-type $(\because)$ and $\Delta F 508 \mathrm{CF}$ littermates $(\square)$. Because separate organs were analysed on individual gels, inter-organ comparison of $\mathrm{NF}-\kappa \mathrm{B}$ activity cannot be made. Error bars indicate SEM.

based on the detection in bronchoalveolar lavage of inflammatory cells and IL-8 in the absence of demonstrable micro-organisms [7, 8]. An alternative explanation for these findings is that the inflammatory response has been successful in eradicating the organism which initially induced it [25]. Several laboratory studies have also suggested a role for mutant CFTR directly inducing inflammation $[10,26]$. In keeping with the clinical studies showing normal IL-8 levels after resolution of infection, no evidence for elevated IL- 8 in unstimulated primary CF nasal epithelial cells could be found. Of nasal swabs from 12 of the CF subjects taken to assess bacterial colonization, one was positive for $S$. aureus, whilst the remaining 11 showed no evidence of bacterial growth. Furthermore, no increase in NF- $\mathrm{KB}$ activation in $\mathrm{CF}$, either in human nasal epithelium or in tissues obtained from $\triangle \mathrm{F} 508 \mathrm{CF}$ mice could be detected. Clearly, one limitation of the whole lung EMSA analysis is the dilution effect of nonepithelial cells which are unlikely to express CFTR. However, the similarity of findings in the human epithelial cells support these data. Consistent with data published by DiMANGo et al. [10] increased NF- $\mathrm{B}$ activity and IL-8 secretion in SCFTE29o- cells was also detected when compared to three wild-type cell lines. However, measurements in two other CF cell lines (CFSMEo-, CFNPE9o-) showed that an increase of $\mathrm{NF}-\kappa \mathrm{B}$ and IL-8 was not a consistent characteristic of
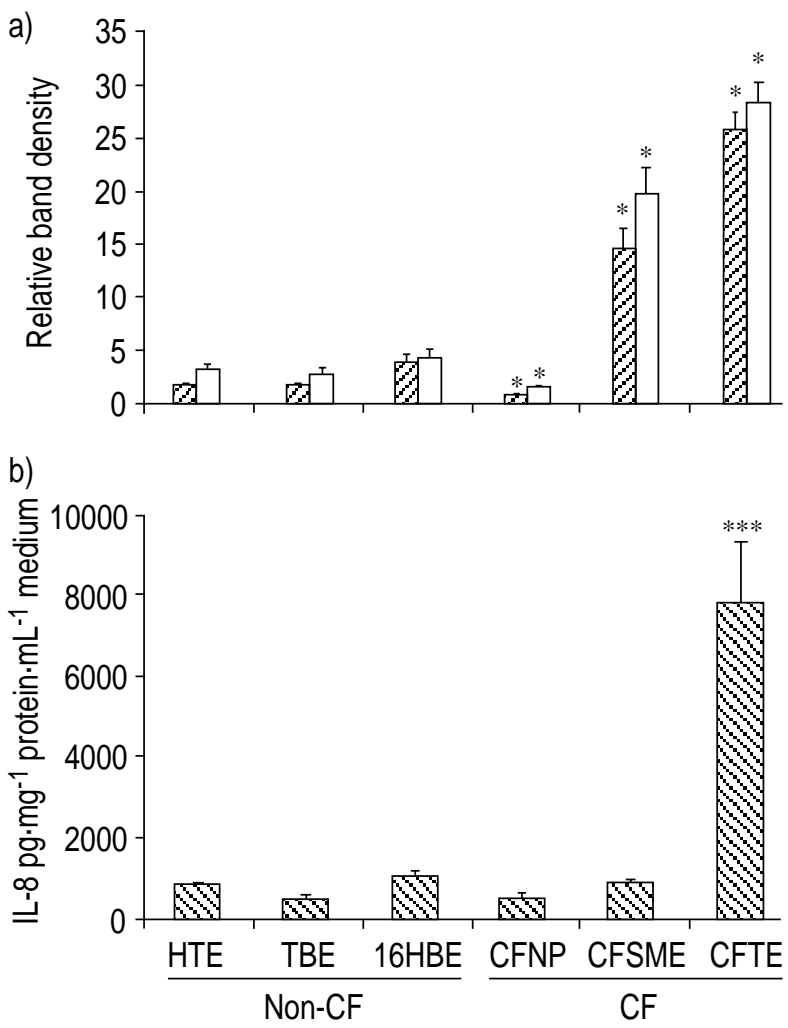

Fig. 6. - Nuclear factor- $\kappa \mathrm{B}(\mathrm{NF}-\kappa \mathrm{B})$ activation and interleukin-8 (IL-8) secretion in unstimulated cystic fibrosis (CF) and non-CF cell lines. Quantification of a) complex II $(\mathbb{Z})$, complex I+II ( $\square$ ) and b) IL- 8 secretion $(n=6, *: p<0.001$, versus mean of non-CF values). Error bars indicate SEM.

such immortalized CF cell lines. Indeed, all combinations of elevated or reduced $N F-\kappa B$ activation and changes in IL-8 could be demonstrated. Whilst the $\Delta$ F508 homozygous line (इCFTE29o-) produced higher levels of IL-8 than the other CF cell lines, a recent paper has demonstrated a similar variability, including that between two $\Delta \mathrm{F} 508$ homozygous cell lines [27].

BAEUERLE et al. [28] have suggested that endoplasmic reticulum (ER) retention of proteins such as mutant CFTR may lead to activation of $N F-\kappa B$ and hence expression of pro-inflammatory cytokines. Cooling of $\Delta$ F508 CF cells has been shown to promote trafficking of $\Delta$ F508 CFTR to the apical membrane. A recent report has suggested that such a reduction in temperature also reduces NF- $\kappa$ B activity and IL- 8 secretion [10]. However, cooling is likely to affect a number of cellular processes, and the present study followed this up by promoting CFTR trafficking using trimethylamine N-oxide (TMAO), which increases $\Delta F 508$ trafficking to the apical membrane in $\Sigma$ CFTE29o- cells. TMAO could restore cyclic adenosine monophosphate (cAMP)-dependent chloride efflux, but did not alter $\mathrm{NF}-\kappa \mathrm{B}$ activity and IL-8 secretion in these cells (data not shown), consistent with the present data, showing lack of effect of different CFTR mutations. Clearly, however, these results may be interpreted as TMAO inducing a low level of trafficking sufficient to restore chloride function, but leaving the vast majority of mutant CFTR mistrafficked. 
a)

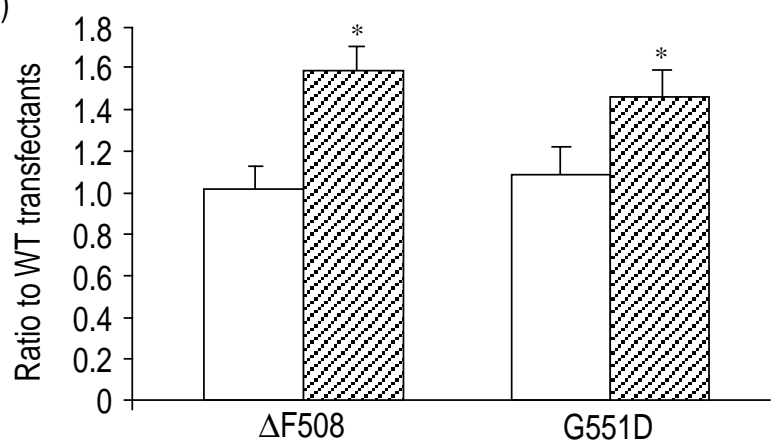

b)

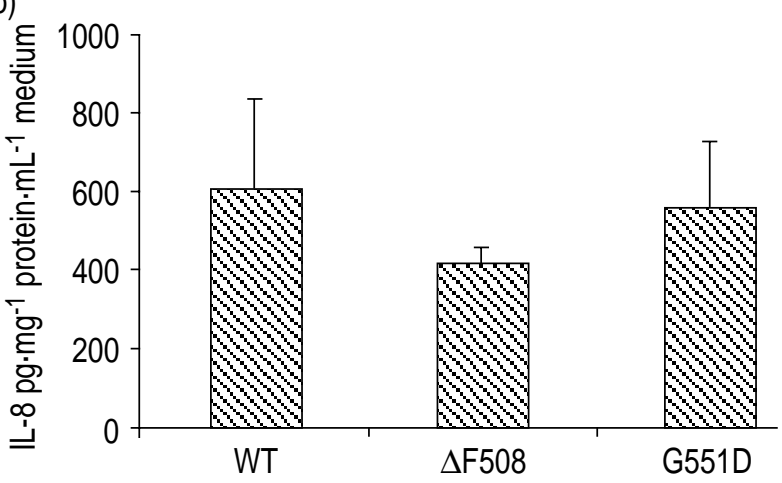

adherence and a preserved capacity for elimination of pathogens, associated with enhanced inflammatory markers as witnesses of recent infection. However, the effects of a chronic inflammatory response, and the continued presence of bacteria (related to increased adherence, excess mucus and probably many other factors), lead to the second phase where the inflammatory process is no longer sufficiently effective to produce bacterial clearance. The present data cannot rule out a direct contribution of the mutant protein on inflammation, but it is suggested that this may be a less significant factor. If these views are correct, novel treatments aimed at reducing bacterial adherence would be expected to play an important role early in life in cystic fibrosis patients. Reducing inflammation at this time may prove harmful, by reducing the appropriate host response to an increased burden. The impact of such treatments later in life will clearly depend on the balance between "useful" and "inappropriate" inflammation. It is likely that only trials of anti-inflammatory treatment can distinguish these possibilities.

\begin{abstract}
Acknowledgements. The authors thank the volunteers who provided the nasal samples, and the staff of the Royal Brompton Hospital Cystic Fibrosis Clinic for their help. In addition, the authors thank T. Pitt for providing the Pseudomonas aeruginosa bacterial strain, D. Gruenert for the cell lines, L. Huang for the DC-Cholesterol/dioleylphosphatidylethanolamine (DOPE) and J. Rommens for the cystic fibrosis transmembrane conductance regulator (CFTR) plasmids.
\end{abstract}

\section{References}

In an attempt to further determine the effect of ER overload, the present study transiently overexpressed wild-type, $\Delta \mathrm{F} 508$ or G551D CFTR protein in Cos-7 cells. These were chosen for their relatively high transfection efficiency and also because these cells have the capability to respond to an inflammatory stimulus, such as TNF- $\alpha$, with increased IL-8 secretion (data not shown). A significant increase in a p50 containing protein/DNA complex (complex II) was detected after $\Delta$ F508 or G551D overexpression when compared to overexpression of the wild-type protein. However, the increased p50 activity was not accompanied by an increase in IL-8 secretion. At present it is uncertain to what extent p50 homo- or heterodimers contribute to IL-8 regulation. ZHU et al. [29] have demonstrated that p65/65 homodimers are responsible for the regulation of IL-8 secretion in human nasal epithelial cells. However, other studies indicate that IL- 8 secretion is regulated through p50/p65 heterodimers [30] and it is likely that regulation varies between cell types.

The present findings are in keeping with the view that increased bacterial adherence contributes significantly to the inflammatory response in cystic fibrosis airways. Host inflammatory responses in cystic fibrosis may be considered in two phases during disease progression. The first phase is characterized by increased bacterial CFTR chloride channel dysfunction in cystic fibrosis. Cell 1993; 73: 1251-1254.

2. Davis PB, Drumm M, Konstan MW. Cystic fibrosis. Am J Respir Crit Care Med 1996; 154: 1229-1256.

3. Goldman MJ, Anderson GM, Stolzenberg ED, Prasad-Kari U, Zasloff M, Wilson JM. Human $\beta$ defensin-1 is a salt-sensitive antibiotic in lung that is inactivated in cystic fibrosis. Cell 1997; 88: 553-560.

4. Knowles MR, Robinson JM, Wood RE, et al. Ion composition of airway surface liquid of patients with cystic fibrosis as compared with normal and diseasecontrol subjects. J Clin Invest 1997; 100: 2588-2595.

5. Pier GB, Grout M, Zaidi TS. Cystic fibrosis transmembrane conductance regulator is an epithelial cell receptor for clearance of Pseudomonas aeruginosa from the lung. Proc Natl Acad Sci USA 1997; 94: 1208812093.

6. Imundo L, Barasch J, Prince A, al-Awqati Q. Cystic fibrosis epithelial cells have a receptor for pathogenic bacteria on their apical surface. Proc Natl Acad Sci USA 1995; 92: 3019-3023.

7. Khan TZ, Wagener JS, Bost T, Martinez J, Accurso FJ, Riches DW. Early pulmonary inflammation in infants with cystic fibrosis. Am J Respir Crit Care Med 1995; 151: 1075-1082.

8. Balough K, McCubbin M, Weinberger M, Smits W,
1. Welsh MJ, Smith AE. Molecular mechanisms of 
Ahrens R, Fick R. The relationship between infection and inflammation in the early stages of lung disease from cystic fibrosis. Pediatr Pulmonol 1995; 20: 63-70.

9. Tirouvanziam R, De Bentzman S, Hinnrasky J, Jacquot J, Teault B, Puchelle E. Early inflammation is a hallmark of proximal and distal human CF foetal airway xenografts. Pediatr Pulmonol 1999; 19: 309.

10. DiMango E, Ratner AJ, Bryan R, Tabibi S, Prince A. Activation of $\mathrm{NF \kappa B}$ by adherent Pseudomonas aeruginosa in normal and cystic fibrosis respiratory epithelial cells. J Clin Invest 1998; 101: 2598-2606.

11. Baeuerle PA, Henkel T. Function and activation of $\mathrm{NF}-\kappa \mathrm{B}$ in the immune system. Annu Rev Immunol 1994; 12: 141-179.

12. Bonfield TL, Konstan MW, Burfeind P, Panuska JR, Hilliard JB, Berger M. Normal bronchial epithelial cells constitutively produce the anti-inflammatory cytokine interleukin-10, which is downregulated in cystic fibrosis. Am J Respir Cell Mol Biol 1995; 13: 257261.

13. Richman-Eisenstat JB, Jorens PG, Hebert CA, Ueki I, Nadel JA. Interleukin-8: an important chemoattractant in sputum of patients with chronic inflammatory airway diseases. Am J Physiol 1993; 264: L413-L418.

14. Douglass JA, Dhami D, Gurr CE, et al. Influence of interleukin-8 challenge in the nasal mucosa in atopic and non atopic subjects. Am J Respir Crit Care Med 1994; 150: 1108-1113.

15. Strieter RM, Standiford TJ, Rolfe MW, Kunnel SL. Cytokines of the Lung. New York, Dekker 1993; pp. 291-305.

16. Pitt TL. Preparation of agglutinating antisera specific for the flagella antigens of Pseudomonas aeruginosa. $J$ Med Microbiol 1981; 14: 251-260.

17. Davies JC, Stern M, Dewar A, et al. CFTR gene transfer reduces the binding of Pseudomonas aeruginosa to cystic fibrosis respiratory epithelium. Am J Respir Cell Mol Biol 1997; 16: 657-663.

18. Pahl HL, Baeuerle PA. A novel signal transduction pathway from the endoplasmic reticulum to the nucleus is mediated by transcription factor $\mathrm{NF}-\kappa \mathrm{B}$. EMBO 1995; 14: 2580-2588.
19. Peterson GL. A simplification of the protein assay method of Lowry et al. which is more generally applicable. Anal Biochem 1977; 83: 346-356.

20. Colledge YM, Abella BS, Southern KW, et al. Generation and characterization of a $\Delta \mathrm{F} 508$ cystic fibrosis mouse model. Nature Genet 1995; 10: 445-452.

21. Bebök ZA, Abai M, Dong J-Y, et al. Efficiency of plasmid delivery and expression after lipid-mediated gene transfer to human cells in vitro. JPET 1996; 279 : 1462-1469.

22. Dean TP, Dai Y, Shute JK, Church MK, Warner JO. Interleukin-8 concentrations are elevated in bronchoalveolar lavage, sputum, and sera of children with cystic fibrosis. Pediatr Res 1993; 34: 159-161.

23. Armstrong DS, Grimwood K, Carlin JB, et al. Lower airway inflammation in infants and young children with cystic fibrosis. Am J Respir Crit Care Med 1997; 156: 1197-1204.

24. Barasch J, Kiss B, Prince A, Saiman L, Gruenert DC, al-Awqati Q. Defective acidification of intracellular organelles in cystic fibrosis. Nature 1991; 352: 70-73.

25. Copenhaver S, Sage A, Vasil A, et al. BALF PCR and ELISA identification of non-culturable Pseudomonas aeruginosa in infants and toddlers with cystic fibrosis. Pediatr Pulmonol 1996; 13: 291.

26. Tabary O, Zahm JM, Hinnrasky J, et al. Selective upregulation of chemokine IL-8 expression in cystic fibrosis bronchial gland cells in vitro and in vivo. Am J Pathol 1998; 153: 921-930.

27. Schwiebert LM, Estell K, Propst SM. Chemokine expression in CF epithelia: implications for the role of CFTR in RANTES expression. Am J Physiol 1999; 276: C700-C710.

28. Baeuerle PA, Baltimore D. NFкB: Ten years after. Cell 1996; 87: 13-20.

29. Zhu Z, Tang W, Gwaltney JM, Wu Y, Elias JA. Rhinovirus stimulation of interleukin-8 in vivo and in vitro: role of NFкB. Am J Physiol 1997; 273: 814-824.

30. Anrather D, Millan MT, Palmetshofer A, et al. Thrombin activates nuclear factor- $\kappa \mathrm{B}$ and potentiates endothelial cell activation by TNF. J Immunol 1997; 159: 5620-5628. 